\title{
“Anna” and the Panel of Psychological Inquiry: The Critic's Perspective
}

\author{
JESS DIGIORGIANNI ${ }^{\text {a,b }}$ \\ a At the time of the Panel, graduate student in the Graduate program in Clinical Psychology, St. Michael's College, \\ Colchester, VT \\ b Correspondence concerning this article should be addressed to Jess DiGiorgianni, Ph.D, M.A., Licensed Mental \\ Health Counselor, Otter Creek Associates, 86 Lake Street, Burlington, VT 05401. \\ Email: JDiGiorgianni@smcvt.edu
}

\begin{abstract}
With an acknowledgment of the difficulty of evaluating the intricacies and implications of any intensely subjective interaction, the critic's function was conceived as dialectical rather than adversarial. Instead of a sustained attack directed against the therapist, this critical effort was formulated as a set of questions, reflections, perplexities, and suggestions designed to create opportunities for a deeper understanding of the intervention. Because the therapy under consideration so conscientiously depicted its work as an act of authentic concern, repeated attempts were made to understand the role that counter-transference played in the unfolding of the therapeutic relationship, an investigative orientation that led to the following overarching question: Is it possible that some of the clinician's great therapeutic strengths, her reservoir of good will, her emotional attunement, her desire to be helpful, her capacity to be moved by the suffering of others, might also to some extent have undermined her therapeutic intent? Embedded in an understanding of psychotherapy as an activity of disappearance in which the therapist disappears by existing solely for the patient, the critical dialectic sought to access this paradoxical vitality in ways that might challenge the loving disappearance of the therapist without losing sight of her poignant contribution to the Freudian project of insightful, compassionate care protected against the unimaginative treatment of both physicians and priests.
\end{abstract}

Key words: panels of psychological inquiry, quasi-judicial method, jury hearing, case study, clinical case study

\section{INTRODUCTION}

The structure of this experiment in therapeutic inquiry has been dealt with extensively in Ronald Miller's (2011) article, "Real Clinical Trials (RCT ${ }^{1}$ ): Transforming Anecdotal Data Into Clinical Facts and Validated Judgments: Introduction to a Pilot Test with the Case of 'Anna"'. Here, however, it is useful for me to address briefly my conceptualization of the role of the "Critic" in this proceeding, as this shaped both the expression and the content of my "critical" efforts. No role in the Panel was more difficult to establish and none was more important in determining just how closely we would follow a legal model in our consideration of the therapeutic details set before us. 
One possible approach in this effort would have been to assume an adversarial posture toward the therapist and Advocate, treating the case as one might a civil trial in which every effort is exerted to disprove the claims being set forth by one's "opponents." This was not the primary spirit with which I undertook this investigative exercise, which I attempted to conduct as an agent of dialectic rather than in a prosecutorial fashion. To have made a commitment tantamount to denying the good work and empathic skill of the therapist in this case would have been not only personally distasteful but an offense against the truth as far as I was able to discern it. As I studied the case, it seemed far more appropriate to raise issues regarding technique, intent, and even optimal efficacy while acknowledging the therapeutic successes described by the therapist and claimed by the Advocate. Thus, the case that I formulated was not in any sustained fashion directed "against" the therapist. Rather, it was conceived as a set of questions, reflections, perplexities, and suggestions designed to create opportunities for a deeper understanding of the intervention. Although at moments it may have resembled an "attack," its project was decidedly not polemical and its hope was to assist in discovering how an admirable therapy might have been conducted with even greater effect.

It was not surprising that some of the judges found this dialectical attitude deficient- I predicted as much in my closing remarks- and there is certainly an argument to be made that a more legal-like, adversarial structure is better equipped to delineate positions, sharpen distinctions, clarify misunderstandings and determine "truth." I would respond that the rich multiplicity of meanings capable of being generated by dialectical processes is the primary desideratum of such a panel of inquiry as we convened and, moreover, that the nuance and ambiguity attendant upon such a dialectic is so central to any truly therapeutic undertaking that it is crucial we learn to live with this condition in our case studies as well as our session hours.

[Note that some of the material presented below because of temporal and thematic constraints and all the problems associated with spontaneity could not be introduced during the actual Panel of Inquiry or was introduced in less elaborate form.]

\section{MY OPENING STATEMENT AS THE CRITIC}

At the center of this dialectical approach is the acknowledgement of uncertainty, a sense of the enormous complexity represented by every therapeutic encounter, which was emphasized in a beginning reference to a well-known practitioner whose humility seemed deserving of emulation (note that the quotes below are what I said or had planned to say):

Bert Karon suggests that the appropriate way to begin any therapy is in a state of confusion. There is so much that is not known, so much to be learned and so many things, perhaps, that will never be learned.

The exhortation to begin therapy in full awareness of one's confusion was extended to the problem of case study, which raises interesting questions about a case study's own therapeutic character:

I think this advice is appropriately extended to the study of any therapy and I freely admit that confusion was my state as I began to study this case and further admit, with no shame or apology, that in certain respects confusion continues to be my prevailing state of mind. 
There is so much to be learned, after all, and so many things that perhaps will never be learned.

The impressive difficulties which attend all attempts to develop an understanding of any human relationship were seen as necessitating the humility implicit in a dialectical stance:

In this impoverished state it would be presumptuous of me to attempt to prove or disprove anything. Perhaps in the course of these proceedings some claims of the Advocate will be weakened but if my role ever seems adversarial I think that this will be the result of my own rhetorical failures or a temporary forgetting of how much I don't yet understand. Rather than as being adversarial, I see the role of critic as one that seeks to promote clarification, explanation and elaboration. This is the spirit with which I have approached the role.

I further described the character of this investigative dialectic with the reminder that any science of subjectivity, if there can ever be such a thing, should not be held to the same criteria of certitude as other, more quantitative disciplines:

In such a therapy as Stacy [Podetz] has conducted, what we have is an experiment with an $\mathrm{N}$ of 1 , with countless variables under imperfect or no control, with the experimental preparation changing on a weekly, a daily, even a momentary basis, with hypotheses that are imperfectly formulated, with data that are extremely difficult to interpret, and, not to be too dramatic, with a human life very much at stake. I am not sure how much clarity one could or should expect under these circumstances. But my intent here is to try to understand what occurred between Stacy and [her client] "Anna," to try to understand what was therapeutic and why it was therapeutic, and perhaps what might have been even more therapeutic.

The recurrent motif of the critical and dialectical analysis, which repeatedly returned to the role that counter-transference played in the therapy, was summarized with special reference to the claims about the case presented by the Advocate:

As I studied the case, one concern became thematic for me, the concern about the role of counter-transference in the therapy that Stacy has described. I will try to raise this concern in a somewhat systematic fashion during our brief afternoon session but I think many of the questions I want to raise about the Advocate's claims also point to counter-transferential aspects of this case. For example, I have wondered whether counter-transference plays a role in the therapist's determination that Anna's cutting was the most pressing therapeutic issue, whether counter-transference feelings provided the basis upon which to adjudicate any conflict between the psychodynamic and humanistic approaches of the therapist, whether counter-transference negatively impacted the efficacy of the therapy, and whether the emotions the client elicited from the therapist played a significant role in her interpretation of the meaning of the client's self-injurious behavior.

A question, pointing to one of the paradoxes that may pervade the therapeutic relationship, was asked about whether some of the therapist's remarkable strengths might also to some degree have undermined her efficacy:

Is it possible that some of Stacy's great therapeutic strengths, her reservoir of good will, her emotional attunement, her desire to be helpful, her capacity to be moved by the suffering of the others, could also have to some extent undermined her therapeutic intent? I am in no 
position to assert that this is the case but it wouldn't surprise me if in this context a great strength also turned out to be something of a weakness. It wouldn't surprise me because that is just the kind of irony I would expect in the realm of any intensely uncertain, intensely nuanced, intricate and reciprocally affective relationship, of which the therapeutic relationship is certainly one.

The opening statement concluded with an expression of gratitude to the therapist for allowing us to consider her therapeutic relationship with Anna and affirmed the celebratory, as well as the critical, nature of this panel:

So for me, at least, this Panel will be a display of my confusion and an attempt to better understand the meanings of therapy and the meaning of the therapy that Stacy conducted. In such a state of uncertainty, there are few things that I feel comfortable asserting without qualification. One of those things is that we are all indebted to Stacy for providing us such rich material to consider and for submitting to the scrutiny and the questioning of this proceeding, just as we are indebted to her for showing such a steadfast care for her client, Anna. Whatever questions I might raise about Stacy's therapy with Anna are in no way intended to lead us to lose sight of the fact that this occasion is largely celebratory, that we are here to celebrate the growth of both Stacy and Anna and the very special relationship they have developed.

\section{THE CASE}

\section{Advocate's Claims}

The Advocate put forward four claims which I had the opportunity to investigate through questions directed toward both the therapist and her supervisor. The kind of concerns I attempted to introduce were entirely consistent with the dialectic spirit described above. I had no interest in disproving any of the advocate's claims, as all four seemed to offer reasonable interpretations of the therapeutic data as it was delivered to us through Ms. Podetz's account of her treatment of Anna. Instead, I engaged these claims by offering alternative perspectives and some competing interpretations with the goal of furthering our exploration of the meanings of the therapy we were charged with evaluating.

Advocate's Claim One: Without reservation, it is absolutely clear that the patient, "Anna”, presented with a serious psychopathology.

I was in agreement that Anna's disturbances were serious although I wanted to raise questions about what appeared to be the identification of her cutting tendencies as the most pressing of her pathological expressions. While I acknowledged Anna's self-mutilating behavior as an important symptom of her distress, I also wanted to develop a better understanding of how the history of her affect, self-understanding, and attachment strategies contributed to her core disturbances. Many of my questions were intended to develop the concern that the therapist had perhaps been overly affected by the patient's self-harm, especially as Anna's self-injurious behaviors were relatively well-contained and she was not obviously suicidal.

For example, Ms. Podetz wrote: 
Although her reasons for seeking counseling on her intake form were anxiety and depression, it became clear very quickly that the more pressing issue was her self-injurious behavior (Podetz, 2008, p.8).

It wasn't clear to me, even in this beginning stage of the therapy, that Anna's self-injurious behavior was indeed the most therapeutically pressing issue. I wondered whether the therapist might have been at risk for missing opportunities to address Anna's anxiety and depression by overemphasizing the importance of her cutting and whether this emphasis was more indicative of the anxiety of the therapist than the urgent character of the symptom.

The possibility that certain therapeutic opportunities could have been missed owing to a preoccupation with the dangers represented by Anna's cutting can be illustrated by considering the relationship between Anna's self-mutilation and her anger: "Anna talked openly about her inability to express anger. She said that anger scared her because she associated it with cutting" (Podetz, 2008, p.23). What was this relationship between cutting and anger? Is the cutting a substitute for anger, an expression of it, its manageable distortion or crystallization, a denial of its existence? Against whom was the anger directed? Anna's parents, herself, her failed loves, an unfair and malicious universe? Is it possible that the therapist, in her haste to get this symptom under control, was not fully open to the possibility of making such questions thematic in the therapy?

I was also interested in examining the connection for Anna between relationships and the cessation of self-injurious behaviors, especially as this related to the therapeutic relationship. Ms. Podetz reported that Anna's cutting stopped when she felt cared for:

Anna spoke about only letting one person take care of her since her grandmother and that was her ex-girlfriend who she dated during eight of the ten months that she abstained from cutting (Podetz, 2008, p.18).

Ms. Podetz also noted that the routine presence of Anna's roommate encouraged her to refrain from cutting:

With her roommate around so often Anna's anxiety and numbness seemed to be reduced. In addition, she mentioned that it would be much more difficult for her to cut even if she wanted. Another relationship was taking the place of her cutting (Podetz, 2008, p. 26).

Was Anna's therapeutic involvement providing her with another relationship to replace the cutting? If so, given the temporary nature of all therapy and especially this one, bounded as it was by the academic year, how indicative of characterological change was the alleviation of this symptom?

Advocate's Claim Two. It is clear that Stacy, the therapist, provided humanistic, psychodynamically informed therapy to "Anna."

While I had no problem conceding that there were both humanistic and psychodynamic elements in the therapy Ms. Podetz conducted, I wanted to investigate what the therapist thought the relationship was between these two approaches. Are the two approaches always 
complementary? Were there any moments in the therapy when these approaches competed with one another or were in tension? If so, was there a principled choice that was made to determine what approach was chosen?

At least one version of Ms. Podetz's stated therapeutic goal seemed to suggest the primacy of a humanistic approach to her client:

My goal was to provide her empathy, acceptance, and unconditional positive regard in the hopes that we would be able to form a genuine therapeutic relationship. This was the foremost thought in my mind throughout each and every session we had together (Podetz, 2008, p. 34).

Even granting with Yalom that it is the relationship that heals (cf. Yalom, 2008, p. 204), is it the relationship, alone, that heals or does the relationship heal, at least in part, because of the "cognitive compress" it applies to the patient's wounds, allowing, for example, certain dissonances to arise in the patient that it becomes necessary to recognize and resolve or, to invoke Freud, encouraging certain aspects of the patient's being to emerge from the caverns of the unconscious into an enlightened consciousness?

Was it possible that Ms. Podetz, in her effort to provide Anna with the kind of supportive, caring, secure environment that would allow her ego to flourish, was not fully available for the challenges that might have promoted a cognitive and therapeutic growth in the patient? This may have been the tension motivating Ms. Podetz's reflective commentary: “Throughout our work together, I tried my best to remain empathic, authentic, and accepting. At times this was more difficult than other times, as she would present inconsistencies that I would want to challenge” (Podetz, 2008, p. 37).

I thought it important to try to discern whether Ms. Podetz's worry about challenging Anna grew so insistent that it may have weakened some of the therapeutic efforts, as illustrated by this description of a key moment in their developing relationship:

I asked if she thought she had been parentified by her parents and if her grandmother had actually allowed her to be a child. She agreed and said that once her grandmother died she began to take care of herself and her parents. Before her words were out, I could see her discomfort and she began defending her parents. I did not challenge her and, instead, accepted her truth” (Podetz, 2008, p. 15).

Was silence the very best response at this stage of the therapy or did Anna go unchallenged just as much from therapist fragility as from her own?

It also seemed important to probe Ms. Podetz's contention that her therapy was without judgment, often thought to be one of the more telling markers of a humanistic methodology:

While working with Anna I maintained a true appreciation of her emotions, history, and growth. I tried very hard to make no judgments, to maintain complete honesty, and to remain open to and validating of her needs (Podetz, 2008, p. 37). 
"Anna" and the Panel of Psychological Inquiry: The Critic's Perspective

Was Ms. Podetz's therapy truly judgment free? Wasn't the "holding function” she imagined herself engaging in essentially a judgment, something like:

You are not well now and in fact part of your not being well is a lack of desire to be well but I will hold this desire for you until you, yourself, are ready to enact this conception, my conception, of health (cf. Podetz, 2008, p. 19).

Advocate's Claim Three. This case demonstrates the capacity of a first year intern to be demonstrably useful in providing therapy to clients in a counseling center, as we maintain that it is highly probable that the treatment resulted in increased health and growth.

In addition to probing the exact nature of the helpful relationship Ms. Podetz skillfully established with Anna, my response to the advocate's claim of therapeutic efficacy called attention to the well known difficulty of establishing convincing measures of therapeutic usefulness. It appeared to me as though most of the specific metrics suggested by the Advocate required further elaboration or admitted of alternative interpretations.

With regard to the claim of Anna's reduction in self-mutilation, it seemed necessary to determine whether the therapist had visual access to the scars and recent cuts of the patient and whether Anna might have been cutting in areas it would have been possible to keep secret. Even under the assumption that Anna's cutting had diminished or even ceased entirely, was it possible that this symptom had been replaced by another, subtler signal of her distress?

Ms. Podetz, for example, had described Anna’s repressive tendencies:

Anna also mentioned that she had always felt the need to protect her mother and that for years she has been suppressing her emotional pain in order to spare her mother emotional pain (Podetz, 2008, p. 10).

Was it possible that Anna had stopped cutting to protect her therapist from the pain of seeing her engaged in this kind of self-damage? Ms. Podetz also described an explicit conversation with Anna about cutting:

I conveyed to her my concern about her cutting and she very sincerely told me that she felt my concern and that she appreciated my attempt to understand (Podetz, 2008, p. 13).

Given Anna's history of pleasing others, taking care of those close to her and worrying about being a burden, is it conceivable that her reduction in self-injury was accomplished as a consolation meant for her therapist? And if Anna's improvement in this area had her therapist's well being, rather than her own, as a kind of emotional center, would this constitute the kind of metric the Advocate had in mind?

This matter of the possible pliability of Anna might have made it difficult to judge her improved functioning in other areas as well. Was the suggested change in affect noticeable by others in the patient's sphere of relationships or was it largely restricted to the therapist's office? Similarly, was her increase in insight expressed in other ways outside the therapy setting? Did 
"Anna" and the Panel of Psychological Inquiry: The Critic's Perspective

her behavior or attitude toward her parents change? Was there a shift in expectations noticed by others? Did Anna come to speak about herself in different ways to her friends?

While Anna's writing did suggest a greater ability to disclose her feelings and attitudes, it seemed important to investigate the import of these changes. If Anna's enhanced ability to reveal herself was not accompanied by a corresponding enhancement of her self-understanding, did the therapy run the risk of helping her to demolish her defenses without encouraging the ego structures necessary for continued progress on the path to wellness? As suggested above, this goes directly to the heart of what it means to be clinically attentive and raises the question of whether anything like a therapeutic catharsis can occur simply through the outpouring of emotion or whether its full and enriching experience requires a cognitive component involving some rational evaluation of affect.

Of course much of what makes it so difficult to adjudicate the claim of usefulness in any therapeutic "experiment" is the wildly imperfect control of all those variables that can have an impact on the result. To frame this complex uncertainty in the context of this case, we might wonder, even granting Ms. Podetz's demonstrable helpfulness, whether this utility consisted primarily of elements that were in some sense peripheral to the therapy, such as the therapist's gender or age or readily accessible warmth, so that Anna's symptoms remain unaddressed at their source? And we might also ask, especially since Ms. Podetz had reported that Anna had not cut herself for 10 months prior to the stress of leaving home and entering college as a freshman, whether she might have improved on her own, after stabilizing in the college environment, without any therapy at all?

Advocate's Claim Four. Stacy's interpretation, that "Anna's” cutting served a self-regulatory function as it offered relief from the tension of both numbness and excessive anxiety, was valid and critical to the client's eventual growth.

The claim that Anna's cutting served a regulatory function, presumably by somatizing her discomfort in way that she could understand and manipulate, appeared to be a reasonable interpretation of her self-injurious behaviors and a possible foundation for helping Anna understand that she could learn to alleviate psychological distress through other, less physically compromising methods. I had, however, hoped to raise the question of whether this interpretation was the most compelling explanation of the phenomenon of self-mutilation in Anna's case and whether any client "confirmation" of this interpretation was the best measure of its validity.

An alternative interpretation was that Anna’s cutting represented her self-disgust, an attitude toward her identity arising from early attachment issues, her parentification, and the consistent impression that her parents did not respect, cultivate, or appreciate her emotional life. Is it possible that both Anna's numbness and her excessive anxiety had their origin in this selfdisgust and that the capacity of her cutting to provide relief revealed her need to express this attitude in an infantile fashion, by using the physical material of her body rather than the representational material of speech?

Of course complex events are often complex by virtue of their many layers of causation so one interpretation does not necessarily exclude the other. Nevertheless, it seemed promising to 
examine whether this alternative interpretation might have led to different treatment strategies, perhaps resulting in a greater utilization of psychodynamic approaches in the pursuit of Anna's wholeness.

\section{MY COUNTER CLAIMS AS THE CRITIC}

In the brief afternoon session of the Panel I sought to strengthen many of the questions I had raised earlier through sustained attention to the role that counter-transference played in the interactions between Ms. Podetz and Anna. Was it possible that the therapy could have been even more effective had a greater awareness and control of its counter-transferential aspects been enacted? Would a compassion without (so much) attachment have better suited the therapeutic aims of Ms. Podetz?

Consistent with the dialectical approach described above, rather than taking on the form of some polemical assertions, the critical counter claims were intended to contribute to a more thorough analysis of the meanings of the therapy by cultivating new perspectives, some of which may have challenged the Advocate's understanding of what had transpired between Ms. Podetz and Anna. As will be clear from the material presented below, this investigative direction was dependent upon Ms. Podetz's forthright and courageous self-reporting, a feature of her presentation to which I continually appealed in developing an understanding of this case and without which our Panel would have been greatly diminished.

Anna's capacity for anger often appeared understated, repressed, distorted, turned inwards, just the sort of deeply hidden reaction that a therapist might seize upon as a possible gateway to important unconscious mechanisms. We see such an opening in this description of an emergency session with Anna:

In that session Anna passionately admitted that she was angry with her father on many levels. I was taken aback when she said this because she had been so adamant in the past about having never felt anger toward her father or anyone else.... I chose not to explore this very deeply" (Podetz, 2008, p. 17).

What was at work in Ms. Podetz's hesitation to make this anger thematic in the therapy?

In her own insightful critique of the therapy, Ms. Podetz made special note of her resistance to encountering Anna's anger as material for the therapeutic work:

As I wrote this case, I also realized that I had missed opportunities to discuss anger she had displayed towards me. There were many instances in which Anna became irritated by my comments and interpretations and showed some anger towards me. I realize that I failed to explore the anger and rather chose to explore the content of the disagreement. I am aware that, had I explored this anger, Anna may have become much more aware of her capacity for anger and may have been able to explore its source” (Podetz, 2008, p. 66).

Was it difficult for Ms. Podetz to probe the feelings that registered Anna's discomfort or to allow herself to become the locus of transferential anger because of a largely unconscious desire to be liked by her patient, because of an overemphasis on the humanistic component of the 
therapy, because she was so attached to her patient that it was sometimes difficult to sit with the suffering of Anna and even cause this suffering when therapeutically felicitous?

Ms. Podetz, herself, provided a speculative measure of what may have been the cost of these missed opportunities through a reference to another case in which an examination of a patient's anger was prominent:

The therapy served to identify her self destructive behavior and make it unacceptable to her by introducing conflict into her defense system. Many transference issues came up for Katie during the therapy as her defense system was continually threatened. Often Katie would become angry with the therapist and the therapist would explore that anger with her until she was able to see its source (Podetz, 2008, pp. 60-61).

By living through Anna's anger together, and especially the anger she sometimes developed toward the therapist, might Anna and Ms Podetz have started the job of "remembering, repeating and working through" in such a way as to gain insight about why Anna had developed the damaging pattern of directing this anger inward?

The reluctance to make her relationship with Anna a therapeutic focus might have also been displayed in Ms. Podetz's avoidance of comparisons to Anna's father. The therapist was made understandably uneasy by the prospect that her proposal that Anna become the subject of a case study would be perceived as an attempt to take advantage of her in a way that was so reminiscent of her father:

I was concerned about her identifying me with her father and identifying the writing of my project as 'using her.' I further explained that my writing would focus more on the power of our therapeutic relationship rather than her cutting or symptoms and that it was a celebration of this relationship and growth. (Podetz, 2008, p. 68)

Was the comparison to Anna's father so quickly subverted by Ms. Podetz because it would have been counter therapeutic to enter into the distrust it might have caused Anna or the uneasiness it could have brought to the relationship? Isn't it conceivable that this distrust and uneasiness could have served the goals of therapy, allowing Ms. Podetz and Anna to examine not only the differences but the similarities between the therapist and her father, thereby expanding Anna's appreciation of interrelational complexity and giving her the chance to feel what it is like to be in a complicated and very human relationship in which she is respected and esteemed and both user and used?

In the truly supportive, caring, and responsive relationship with Anna that Ms. Podetz so carefully formed and carried through, I wondered if there wasn't too much urgency, too much worry, too great a desire to protect and to replace suffering with a serenity that may have been premature. Perhaps we can hear the anxious responsibility in the therapist's voice when she describes the impactful interlude of a brief school vacation:

It was the week after October break so I knew that the transition from college to home and then from home to college must have triggered her anxiety and subsequent cutting. I couldn't help feeling responsible for her relapse. I had known transitions were difficult for her but she 
had been doing so well that I thought she would be able to handle it and I didn't prepare properly for it (Podetz, 2008, p. 16).

Is it possible that in her admirable devotion to Anna and the "holding function" which she assigned to herself, Ms. Podetz developed an attachment which at times so overwhelmed her that her desire for Anna to be healthy did not leave enough room for Anna's own desire to flourish:

During that session, I felt an intense desire for Anna to be healthy. It was more intense and very different form my feelings with other clients and I recognized this immediately as it overwhelmed me. After the session, I closed my office door and sat with the intense emotions. I reflected on my experience with her and wondered whether my overwhelming desire for her to be well was, in fact, her overwhelming desire to be healthy. I wondered whether I was holding it for her because it was too much for her to bear ( Podetz, 2008, p. 19).

Is it conceivable that during some moments of the therapy Ms. Podetz was subject to the kind of panicked solicitude about Anna's well being that would not permit her to take some of the risks mandated by a challenging, insight-based therapy which makes itself ultimately dependent on the self-actualizing potential of the patient? Ms. Podetz's citation from a paper by Connors captures at least part of this apprehension with an appropriate emphasis on the physically imperiling behavior of patients:

Many professionals feel a sense of urgency when self-injury is disclosed, and thus abandon the more thoughtful, empathic, and empowering stance they might otherwise employ (Podetz, 2008, p. 43).

Finally, I wanted to inquire whether there was any danger that Ms. Podetz's therapeutic posture called forth another comparison with Anna's father. We know that Anna had a propensity to idealize her father:

During that session, Anna was talking about how she makes sense of the world when she said, 'my father making sense, makes sense and that is how I make sense of my life.' Her idealization of her father had never been more evident and I was now very aware of why she so obstinately denied ever being angry with him (Podetz, 2008, p. 20).

Could Ms. Podetz's “holding function,” her avoidance of Anna's anger, her sense of urgency, her eagerness to protect and rescue Anna, have all conspired to encourage Anna to exchange one meaning maker in her life, her father, for another, her therapist?

\section{REFLECTIONS: PSYCHOTHERAPY AS FÜRSORGE (AUTHENTIC CARE)}

As I write this summary a year after the panel took place, a year which for me was intensely clinical, filled with new experiences calling forth new ideas about what might constitute a truly therapeutic being, I remain transfixed by the sheer beauty of Ms. Podetz's attendance upon her patient, Anna. Whatever questions I may have competently raised about the 
therapy's conceptualizations, strategies, and efficacy could never detract from what we had and continue to have before us, Ms. Podetz's compelling account of two people coming to care about one another in ways that promoted healing, hope, and enlightened self-awareness.

As I have occasionally reflected on this case over the past year, I have grown accustomed to thinking of Ms. Podetz's work as a remarkable exemplification of psychotherapy as Fürsorge. In Being and Time, Heidegger contrasts two "extreme possibilities" for understanding "concern" in its "positive modes," one of which turns out to be not so "positive:”

[Concern] can, so to speak, take the other's 'care' away from him and put itself in his place in taking care, it can leap in for him. Concern takes over what is to be taken care of for the other. The other is thus displaced, he steps back so that afterwards, when the matter has been attended to, he can take it over as something finished and available or disburden himself of it completely. In this concern, the other can become one who is dependent and dominated even if this domination is a tacit one and remains hidden from him (Heidegger, 1996, p. 114).

This inauthentic concern, so starkly ubiquitous in those pharmacologically informed reflexes which "leap in" for the patient, "taking care away" and creating a patient who has been deformed by having become “dependent and dominated,” is precisely what Ms. Podetz's therapy so eloquently speaks against. In contrast to this dehumanizing, debilitating concern which, as Heidegger says, does the job and "takes the other's 'care' away," is another possibility, "a concern which does not so much leap in for the other as leap ahead of him, not in order to take 'care' away from him, but to first give it back to him as such” (Heidegger, 1996, p. 115). This is the authentic concern which illuminated the therapy that Ms. Podetz and Anna shared together, the concern which "essentially pertains to authentic care," that is, which pertains "to the existence of the other and not to a what which it takes care of," thereby helping "the other to become transparent to himself in his care and free or it” (Heidegger, 1996, p. 115). Informed by such an understanding of this case and the care and concern it exhibited, my closing statement, presented below without commentary, endeavored both to acknowledge the liberating character of Anna's therapy as well as to ask what properties might set apart a truly liberating therapeutic relationship from other human interactions.

\section{MY CLOSING STATEMENT AS THE CRITIC}

My closing statement as the critic was as follows:

We have had the opportunity here to examine a resplendent therapy, resplendent, I think, because it is about two people falling in love and because it demands that we ask the question: What is the best way for us as therapists to love our patients?

Much of the most insightful therapeutic literature devotes itself to the question of the uncommon character of therapeutic love and Stacy introduces this problem herself towards the end of her thesis when, in the context of explaining her reluctance to diagnose Anna as someone with a borderline personality disorder as a reluctance to be limited by labels, she quotes from an article by Turp that cites Bion: : "Our best beginning is to accept not to know and to engage with the situation "without memory or desire." 
How do we love without memory or desire? Is this really the therapeutic task? And if it is, has Stacy managed to accomplish this? These are a few of the questions that Stacy's case study raises for me and perhaps, now, they are your questions as well.

I have meant to ask these questions as a way of celebrating those therapeutic strengths that Stacy has so obviously displayed throughout her work with Anna and to which I referred in my opening statement, her heart of being helpful, her compassionate response to the suffering of others, her commitment to caring. Thank you, again, Stacy, for submitting your work to such scrutiny, for courageously entertaining alternative theoretical perspectives and the numberless questions that arise from considering the complex and necessarily incomplete history of a human and very special relationship.

I don't think it is appropriate that I have the last word in this inquiry, even though the format seems to suggest this. I want to offer Stacy the remainder of my time, if she wants it, to offer any commentary she considers relevant. We have been granted the unique privilege of considering her work and I think it only fitting that we leave with her words.

I would just like to conclude with the following question. If there is any validity to the suggestion that Stacy's therapy was to some degree impeded by counter-transference feelings, is it possible to express this impediment in the following way: At some points in the therapy did Stacy conduct herself with the understandable and very human hope that in the future she might retain a special place in the heart of Anna, a unique place in her vision of recovery and health, a vision that could quite rightly be claimed as a result of their collaborative efforts, and could it be that this hope was in conflict with what may not only be the best beginning but the best end of a therapy that is conducted without memory or desire? Let me try to synthesize this unwieldy question in a way that might be less cryptic: Is it possible that the goal of the therapist should be, rather than to be remembered, to be forgotten?

\section{JUDICIAL AND OTHER OUTCOMES}

While the critical dialectic was primarily designed to be elaborative rather than competitive, it was nevertheless opposed to the Advocate's claims in the formal judicial review of the case implemented by the Panel. Even if the critical arguments had been more adversarial and directly challenging, I think there is little doubt that the authentic concern which the therapy embodied would have, and should have, impressed the judges to rule in the Advocate's favor. The judges' deliberations, described in greater detail in the Panel overview, resulted in an almost unanimous affirmation of all of the Advocate's claims and essentially produced a deadlock in the assessment of the critical counterclaim, that counter-transference had to some degree negatively impacted the therapeutic work of Ms. Podetz and Anna.

For me, however, the most poignant impact of the critical dialectic and the Panel's inquiry may have been revealed in the closing commentary of Ms. Podetz, who had indeed taken advantage of my offer to bring the day to a close. In her final remarks she mentioned that she had long been contemplating her last session with Anna, which at the time of the Panel had not yet taken place and was rapidly approaching. She observed that she had been planning to offer Anna a parting gift, a book if I remember, by way of acknowledging the very special, therapeutic relationship they had developed. As a result of the Panel's proceedings, however, Ms. Podetz 
offered that she was rethinking this decision and would probably refrain from such a gesture. I am uncertain about what actually happened on that last day between Anna and her therapist but I hope Ms. Podetz resisted the very human temptation to give Anna some commemorative object. Better, I think, to have restricted the session to the realm of the symbolic and to have had faith in the magic of words and the re-creative powers of pure memory. Better to have hoped for so successful an integration into Anna's being of the therapy's authentic concern that its meanings grow more and more illuminative as its details fade slowly into life's background. In any case, a gift had already been given. Ms. Podetz, herself, was that gift.

\section{REFERENCES}

Heidegger, M. (1996). Being and time. Albany, NY: State University of New York Press. Miller, R.B. (2011). Real Clinical Trials $\left(\mathrm{RCT}^{1}\right)$ - Panels of Psychological Inquiry for transforming anecdotal data into clinical facts and validated judgments: Introduction to a pilot test with the case of "Anna." Pragmatic Case Studies in Psychotherapy, 7(1), Article 2, 6-36. Available: http://hdl.rutgers.edu/1782.1/pcsp_journal

Podetz, S. (2008). Seeing beyond the scars: A case study of “Anna.” Master's thesis in psychology, Saint Michael's College, Colchester, Vermont. Note: see Podetz, 2011, in this PCSP issue.

Podetz, S. (2011). Seeing beyond the scars: A testament to “Anna.” Pragmatic Case Studies in Psychotherapy, 7(1), Article 3, 37-63. Available: http://hdl.rutgers.edu/1782.1/pcsp_journal Note: After the Panel of Inquiry described in Miller (2011) was completed, Podetz's masters thesis was reformatted and copyedited to meet the guidelines of a PCSP case study, and some of the broader literature review was shortened. Aside from these two differences, the substance of Podetz's 2008 and 2011a versions of the case study of Anna are identical.

Yalom, I. (2008). Staring at the sun. San Francisco, CA: Jossey-Bass 